\title{
Tumor Progression Stage and Anatomical Site Regulate Tumor-Associated Macrophage and Bone Marrow-Derived Monocyte Polarization
}

\author{
Elizabeth F. Redente, ${ }^{*}$ Lori D. Dwyer-Nield, ${ }^{*}$ \\ Daniel T. Merrick, ${ }^{\dagger}$ Komal Raina, ${ }^{*}$ \\ Rajesh Agarwal, ${ }^{*}$ William Pao, ${ }^{\ddagger}$ Pamela L. Rice, ${ }^{\S}$ \\ Kenneth R. Shroyer, " and Alvin M. Malkinson* \\ From the Departments of Pharmaceutical Sciences," and \\ Pathology, ${ }^{\dagger}$ University of Colorado, Aurora, Colorado; the \\ Department of Medicine, ${ }^{\ddagger}$ Memorial Sloan-Kettering Cancer \\ Center, New York, New York; the Division of Pulmonary Biology, \\ Veterans Affairs Medical Center, Denver, Colorado; and the \\ Departments of Medicine and Pathology, "Stony Brook \\ University, Stony Brook, New York
}

Tumor-associated macrophages (TAMs) encourage and coordinate neoplastic growth. In late stage human lung adenocarcinoma, TAMs exhibited mixed

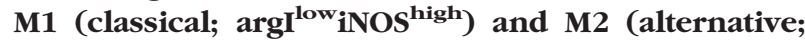
$\operatorname{argI}^{\text {high }}{ }^{\text {iNOS }}{ }^{\text {low }}$ ) polarization based on arginine metabolism. In several murine cancer models including chemically and genetically-induced primary lung tumors, prostate tumors, colon xenografts, and lung

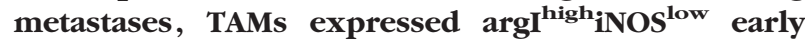
during tumor formation; argI $^{\text {low }_{\text {iNOS }}}{ }^{\text {high }}$ polarization also occurred during malignancy in some models. In a chemically-induced lung tumor model, macrophages expressed $\operatorname{argI}^{\text {high }_{\text {iNOS }}}{ }^{\text {low }}$ within one week after carcinogen treatment, followed by similar polarization of bone marrow-derived monocytes (BDMCs) a few days later. TAMs surrounding murine prostate tumors also expressed argI $^{\text {high }_{\text {iNOS }}}{ }^{\text {low }}$ early during tumorigenesis, indicating that this polarization is not unique to neoplastic lungs. In a human colon cancer xenograft model, the primary tumor was surrounded by argI $^{\text {high }}{ }_{\text {iNOS }}{ }^{\text {low }}$-expressing TAMs, and BDMCs also expressed argI $^{\text {high }}{ }_{\text {iNOS }}{ }^{\text {low }}$, but pulmonary macrophages adopted argI $^{\text {high }}$ iNOS $^{\text {low }}$ polarization only after tumors metastasized to the lungs. Persistence of tumors is required to maintain TAM polarization. Indeed, in both conditional mutant Kras- and FGF10driven models of lung cancer, mice expressing the transgene develop lung tumors that regress rapidly when the transgene is silenced. Furthermore, pul- monary macrophages expressed $\operatorname{argI}^{\text {high }_{\text {iNOS }}}{ }^{\text {low }}$ on tumor induction, but then returned to $\operatorname{argI}^{\text {low }}$ iNOS ${ }^{\text {low }}$ (no polarization) after tumors regressed. Manipulating TAM function or depleting TAMs may provide novel therapeutic strategies for preventing and treating many types of cancer. (Am J Pathol 2010, 176:2972-2985; DOI: 10.2353/ajpath.2010.090879)

Resident and newly infiltrating macrophages are key leukocyte populations that regulate production of inflammatory mediators to warn of injury and initiate tissue repair during cancer-associated inflammation. ${ }^{1,2}$ The destiny of macrophages is at least partly determined during their ontogeny in the bone marrow. Monocyte precursors differentiate to become either macrophages that reside normally in tissues or inflammatory macrophages that respond to chemokine signals and infiltrate into the affected tissue to mount a response. ${ }^{3}$ During tumorigenesis, macrophages infiltrate tumors and surrounding tissue. However, unlike scenarios where macrophages are involved in host defense, tumor associated macrophages (TAMs) support rather than hinder neoplastic growth, as shown by histopathological, epidemiological, pharmacological, and genetic studies. ${ }^{4}$ TAMs were first observed 150 years ago by Virchow, ${ }^{5}$ and current evidence associates chronic inflammatory diseases such as bronchitis, inflammatory bowel disease, gastritis, and colitis with increased risk of cancer development. ${ }^{2}$ This synergistic co-evolution of cancer and inflammation continues when tissues are damaged by aggressive cancer growth. Anti-

Supported by National Cancer Institute 033497 and 132552 (to A.M.M.), CA113876 (to R.A.), and National Institutes of Health Special Program of Research Excellence program PA50CA058187 (to D.T.M.)

Accepted for publication January 27, 2010.

W.P. is a consultant for Molecular MD.

Supplemental material for this article can be found on http://ajp. amjpathol.org.

Address reprint requests to Lori D. Dwyer-Nield, Ph.D., Department of Pharmaceutical Sciences, University of Colorado Denver, C238-P15 RII, 12700 East 19th Avenue, Aurora, CO 80045. E-mail: Lori.Nield@ ucdenver.edu. 
inflammatory drugs such as sulindac and aspirin inhibit colon polyp formation in colorectal cancer patients, ${ }^{6}$ while polymorphisms in genes regulating inflammation control susceptibility to lung cancer in both mice ${ }^{7}$ and humans. ${ }^{8}$ Overexpression of anti-inflammatory signals ${ }^{9,10}$ depresses cancer growth, whereas mutations that enhance inflammatory responses augment tumorigenesis. ${ }^{11}$

Macrophages exhibit a wide phenotypic diversity and exert multiple pathobiological effects ${ }^{12}$ that support and encourage tumor growth, including the release of proangiogenic factors such as VEGF, ${ }^{13} \mathrm{EGF},{ }^{14}$ and proteases that digest normal tissue to provide a route for vessel intravasation and metastatic invasion of tumor cells. Macrophages also suppress the activities of $\mathrm{CD} 4^{+}$and $\mathrm{CD} 8^{+}$ lymphocytes by secreting chemokines that attract T-regulatory cells to dampen adaptive immune surveillance against tumors. ${ }^{15,16}$

Two macrophage activation phenotypes, M1 and M2, characterize extremes along a gradient of activation and are regulated by the relative abundance of $T_{H} 1$ and $T_{H} 2$ cytokines. In vitro, mature macrophages demonstrate plasticity by shuttling back and forth between these activation pathways. ${ }^{17,18}$ Macrophages classically/M1 polarized by exposure to interferon (IFN)- $\gamma$ or LPS produce interleukin (IL)-6 and IL-12, and up-regulate inducible nitric oxide synthase (iNOS) to produce nitric oxide (NO) and citrulline. Alternative/M2 polarization is induced by exposure to IL-4 and IL-13, cytokines that bind to a common receptor subunit, IL-4R $\alpha .{ }^{19} \mathrm{M} 2$ macrophages produce anti-inflammatory IL-10, up-regulate expression of the mannose receptor and arginase I, as well as macrophage-specific genes including Ym1 and Fizz1. Polyamines are produced, and the iNOS substrate, arginine, is depleted in M2 polarized macrophages. ${ }^{12,20-22}$ These changes in macrophage phenotype have functional consequences. NO produced by M1 macrophages can kill other cells by combining with oxygen radicals to form toxic peroxynitrite. ${ }^{23}$ Ornithine produced by M2 macrophages can be exported and taken up by tumor cells to serve as precursors for DNA synthesis. ${ }^{24}$ Some macrophages express both arginase and iNOS enzymes (M1 + M2), which can act synergistically, as well as independently, to limit $T$ cell function. A recent study illustrating the clinical significance of M2 polarization by TAMs demonstrated that mice vaccinated against the asparaginyl endopeptidase, legumain, which is highly and specifically expressed in M2 macrophages, primed lymphocytes against this M2 antigen. Subsequent killing of M2 macrophages by $\mathrm{CD}^{+}$lymphocytes inhibited the growth of breast cancer xenografts. ${ }^{25}$ The $\mathrm{T}_{\mathrm{H}}{ }^{2}$ cytokines that regulate M2 TAM activation are associated with many neoplasias, including non-small cell lung (NSCLC), ${ }^{26}$ breast, ${ }^{25}$ and ovarian cancer. ${ }^{27,28}$

We recently characterized stromal cell composition during primary lung cancer progression induced in $A / J$ mice by urethane,$^{29}$ an animal model of pulmonary adenocarcinoma (AC). ${ }^{30}$ Macrophages accumulated adjacent to, but outside of, tumors. As tumors progressed to malignancy, macrophage numbers increased, and their polarization changed. ${ }^{29}$ Pulmonary macrophage arginine metabolism was assessed to determine their polarization state. Naïve A/J mice expressed very low levels of arginase I and iNOS (argl ${ }^{\text {lowiNOS }}{ }^{\text {low }}$ ), constituting an unpolarized phenotype. TAMs in mice bearing benign tumors expressed arginase I (argl ${ }^{\text {highiNOS }}{ }^{\text {low; }}$ M2 polarized), whereas macrophages associated with malignant tumors expressed iNOS (argl ${ }^{\text {lowiNOS }}{ }^{\text {high; }}$ M1 polarized). Local pulmonary macrophages were not the only population affected by signals emanating from tumors in this study. Polarization of monocytes extruded from the bone marrow (bone marrow-derived monocytes [BDMCs]) mirrored that of TAMs, switching from argllowiNOS ${ }^{\text {low }}$ in control mice to argl $^{\text {high }}$ NOS $^{\text {low }}$ in adenoma-bearing mice, and then to argl ${ }^{\text {lowiNOS }}{ }^{\text {high }}$ when carcinomas had developed. ${ }^{29}$ BDMCs thus underwent tumor-directed differentiation while still in the bone marrow before entering the circulation and infiltrating the lungs to become TAMs. This suggests that the differentiation status of circulating monocytes could be evaluated as a diagnostic tool for monitoring lung cancer progression.

Herein, we assess the arginine metabolic phenotype of macrophages and BDMCs during tumorigenesis to assess polarization in response to different carcinogens, at different organ sites, and in genetic models, thus testing the specificity of the macrophage response to tumors, their location, and at different stages of tumorigenesis. We find correlations between these experimental models and human disease.

\section{Materials and Methods}

\section{Human Lung Cancer Sample Acquisition}

Fourteen histological specimens of pulmonary AC were selected on the basis of availability of adequate tissue for immunohistochemical evaluation from archival collections maintained by the Department of Pathology, University of Colorado Denver under the auspices of the COMIRB. These tumors had been previously classified as well-differentiated, moderately-differentiated, or poorly-differentiated.

\section{Macrophage Polarization in Formalin-Fixed} Tissue

Human tumor biopsy and surrounding stromal tissue and mouse lung tissue were examined for macrophage infiltration and polarization status by immunofluorescence using antibodies against F4/80 to identify macrophages, iNOS to detect M1 polarization, and mannose receptor (human) or arginase I (mouse) to detect M2 polarization, using procedures described previously ${ }^{29}$ and summarized in Table 1. Briefly, sections were deparaffinized and rehydrated through a series of ethanol washes, and antigens retrieved in boiling $100 \mathrm{mmol} / \mathrm{L}$ citrate buffer followed by a 40-minute autofluorescence block with 10 $\mathrm{mg} / \mathrm{ml}$ sodium borohydride in PBS. Samples were first blocked with avidin-biotin solution (Vector Laboratories, Burlingame, CA), followed by exposure to the primary and biotinylated secondary antibodies (Table 1) and detection with fluorescent avidin conjugates. 
Table 1. Antibodies and Conditions for Immunofluorescence

\begin{tabular}{ccccc}
\hline \multicolumn{1}{c}{ Antibody } & Dilution & Secondary & Sample type & Fluorophore/color \\
\hline $\begin{array}{l}\text { F4/80-polycolonal (Caltag } \\
\text { Laboratories, Carlsbad, CA) }\end{array}$ & $1: 100$ & Rat & $\begin{array}{c}\text { BAL, human and mouse pulmonary macrophages, } \\
\text { peritoneal macrophages }\end{array}$ & Fluorescein/green \\
$\begin{array}{l}\text { CD-68-monocolonal (Dako, } \\
\text { Glostrup, Denmark) }\end{array}$ & $1: 100$ & Mouse & BDMCs, xenograft TAMs, prostate TAMs & Fluorescein/green \\
$\begin{array}{l}\text { Arginase l-polyclonal (Santa Cruz } \\
\text { Biotech, Santa Cruz, CA) }\end{array}$ & $1: 100$ & Goat & Murine M2 activation & AMCA/blue \\
$\begin{array}{l}\text { CD-206/Mannose } \\
\text { receptor-monoclonal (Serotec, } \\
\text { Oxford, UK) }\end{array}$ & $1: 100$ & Human & Human M2 activation & AMCA/blue \\
$\begin{array}{l}\text { iNOS-polyclonal (BD Pharmagen, } \\
\text { San Diego, CA) }\end{array}$ & $1: 100$ & Rabbit & Mouse and human M1 activation & Rhodamine/red \\
\hline
\end{tabular}

\section{Chemically Induced Lung Tumor Models}

$\mathrm{A} / \mathrm{J}, \mathrm{FVB}, \mathrm{BALB} / \mathrm{CByJ}$ (hereafter, cBy), BALB/CJ, and C57BL/6J (hereafter, B6) male and female mice 4 to 6 weeks of age were purchased from Jackson Laboratory (Bar Harbor, ME), housed on hardwood bedding with 12-hour light/dark cycles, and fed standard rodent diet (Harlan Teklad, Madison, WI) at the Center for Laboratory Animal Care at the University of Colorado Denver under a protocol approved by the University of Colorado Institutional Animal Care and Use Committee. For single agent carcinogenesis, male $\mathrm{A} / \mathrm{J}, \mathrm{FVB}$, and $\mathrm{B} 6$ mice were injected i.p. (intraperitoneally) with $1 \mathrm{mg}$ urethane (ethyl carbamate; Sigma, St. Louis, MO)/g body wt dissolved in sterile $0.9 \% \mathrm{NaCl}$ as previously described ${ }^{31}$; control mice received a single saline i.p. injection. Animals were sacrificed at days 1, 2, 7, 14, and 21 and weeks 16, 24, 32, and 42 after urethane exposure as indicated in each experiment. Macrophages present in the bronchoalveolar lavage (BAL) and BDMCs were isolated (see below) from 4 to 5 mice per time point and lungs prepared for histological examination from 4 to 5 additional mice per time point. To determine tumor multiplicity in A/J, FVB, and B6 at 24 and 42 weeks after urethane exposure, lungs were removed from control and treated animals, and tumors were dissected from surrounding tissue and counted using a dissecting microscope with fiberoptic lighting. Because $\mathrm{BALB} / \mathrm{c}, \mathrm{cBy}$, and B6 mice are more resistant to carcinogenesis than $A / J$, these strains received multiple i.p. injections, consisting of $1 \mathrm{mg} / \mathrm{g}$ urethane i.p. once per week for 7 weeks to induce lung tumors; control mice received 7 weekly saline vehicle injections. These mice were sacrificed 24, 32, and 42 weeks after the initial injection, and samples were processed as described above.

We also examined the universality of macrophage polarization in chemically-induced primary mouse lung tumors in which the proto-oncogene Kras is mutated at a different codon than in the urethane model and in which macrophage infiltration has been shown to augment tumor formation. ${ }^{32}$ In 2-stage initiation/promotion carcinogenesis studies, mice were injected once i.p. with 10 $\mathrm{mg} / \mathrm{kg}$ 3-methylcholanthrene (MCA; Toronto Research Chemicals, Inc., Ontario, Canada) followed by six onceweekly injections of butylated hydroxytoluene (BHT; Sigma, $100 \mathrm{mg} / \mathrm{kg}$ BHT week one, $200 \mathrm{mg} / \mathrm{kg}$ weeks 2-6) in corn oil as previously described. ${ }^{32,33}$ Age-matched control mice were injected with equal volumes of corn oil vehicle $\left(\right.$ Mazola $\left.^{\circledR}\right)$. Animals were sacrificed at 24, 32, and 42 weeks after the initial MCA injection, and samples were prepared as described above.

\section{Isolation of Pulmonary Macrophages by BAL}

Mice were sacrificed by lethal i.p. pentobarbital injection, their tracheas cannulated, and lungs lavaged three times with $1 \mathrm{ml}$ PBS containing $0.6 \mathrm{mmol} / \mathrm{L}$ EDTA. ${ }^{34}$ The supernatant from the first lavage was saved for cytokine analysis. Inflammatory cell infiltration was determined by pooling lavaged samples from each mouse and counting cells using a hemocytometer. Differential cell counts were based on cell morphology as determined by Wright/Giemsa staining, and infiltrating cells classified as monocytes/macrophages, lymphocytes, neutrophils, or eosinophils. In naïve mice, 90 to $100 \%$ of BAL cells are macrophages, a percentage that decreases during tumor formation when additional inflammatory cell types infiltrate the lungs. ${ }^{29}$

\section{Preparation of BDMCs}

One femur was removed from each of the mice described in the previous section and bone marrow cells harvested by flushing $1 \mathrm{ml}$ of sterile PBS through the bone marrow cavities with a $255 / 8$ gauge syringe. ${ }^{29}$ Cell numbers were determined, 20,000 cells were cytospun onto a slide, and differential cell counts were performed as above. On average, 2 to $4 \%$ of the extruded bone marrow cells are monocytes.

\section{Isolation of Peritoneal Macrophages}

Peritoneal macrophage harvest was performed before BAL in A/J mice 24 and 42 weeks after a single urethane injection. The abdominal cavity was lavaged with $10 \mathrm{ml}$ of sterile PBS injected i.p. for 1 minute, after which fluid was removed using a $10-\mathrm{ml}$ syringe. Peritoneal cells were counted and 20,000 cells cytospun onto a slide; differential counts were performed as above.

\section{Iron Prussian Blue Staining of Bone Marrow Macrophages}

One femur from each $\mathrm{A} / \mathrm{J}, \mathrm{cBy}$, and $\mathrm{B} 6$ control and urethane-treated mouse was removed and decalcified in $8 \%$ 
formic acid solution for 3 hours and formalin fixed. Resident bone marrow macrophages were stained with Iron Prussian blue stain containing hydrochloric acid and potassium ferrocyanide. Sections were counterstained with nuclear fast red solution (University Hospital Histology Laboratory, Denver, CO).

\section{Immunofluorescence Analysis of the Polarization States of Macrophages and BDMCs}

Immunofluoresence was performed on BAL macrophages and BDMCs as described. ${ }^{29}$ Table 1 denotes the antibody conditions, sources, and fluorophores used. Primary antibody binding to iNOS, arginase I, CD-68 (BDMCs), and F4/80 (BAL macrophages) was detected using biotin-conjugated IgG secondary antibody (Vector), after incubation with rhodamine, 7-amino-4-methylcoumarin-3acetic acid (AMCA) and fluorescein fluorescent avidin conjugates (Vector), respectively. A digital deconvolution microscopy imaging system attached to a Zeiss Axioplan 2 epi-Fluorescence upright microscope was used to image fluorescent staining. ${ }^{29}$ Fluorescent images are $\times 630$ final magnification. For all samples, macrophages and monocytes that display no detectable arginase I or iNOS staining are designated as argl ${ }^{\text {low/iNOS }}{ }^{\text {low }}$. Macrophages that display argl high/iNOSlow staining are M2 or alternatively polarized, and macrophages that immunostained argl $^{\text {low/iNOS }}{ }^{\text {high }}$ classified as M1 or classically polarized. Argl $^{\text {high }} /$ iNOS $^{\text {high }}$ stained macrophages are classified as M1 + M2. Colocalization of the binding of different antibodies to the same cell is detected by using multiple fluorescent stains. Semiquantitative estimates of protein expression were determined by comparing fluorescent staining exposure times (msec) of treated and control cells.

\section{Quantitation of BAL IFN- $\gamma$ and IL-4 Contents by ELISA}

IFN- $\gamma$ and IL-4 contents in BAL fluid were assayed by ELISA, according to the manufacturer's instructions (R\&D Systems, Minneapolis, MN).

\section{Transgenic Adenocarcinoma of the Mouse Prostate Model}

Transgenic adenocarcinoma of the mouse prostate (TRAMP) mice develop early spontaneous prostatic intraepithelial neoplasia (PIN) lesions of the dorsolateral prostate that progress to late-stage metastatic AC over the course of six months. This models the progression of human prostate cancer ${ }^{35}$ and is thus clinically relevant. Regulatory elements of the minimal rat probasin (rPB) promoter gene encode androgen related protein, which specifically drives expression of SV40 early genes (T/t; Tag) in prostatic epithelium. ${ }^{36}$ This hormonally regulated transgene is expressed at sexual maturity to effect neoplastic epithelial transformation. ${ }^{37}$ Formalin-fixed prostate tissue specimens obtained from TRAMP B6 male mice ${ }^{38}$ at different stages of neoplastic progression were histologically characterized as PIN, well-, moderately-, or poorly-differentiated AC. Four slides from each group were examined for macrophage infiltration and polarization state by immunofluorescence as described above.

\section{Mutant Kras Transgenic Lung Cancer Model}

Bitransgenic FVB mice that express Doxycycline (Dox)inducible $K$-Ras $4 b+{ }^{G 12 D}$ under the control of the CCSP promoter ${ }^{39}$ were treated with Dox $(0.5 \mathrm{mg} / \mathrm{ml}$ in the drinking water) to induce development of spontaneous proliferative foci that progressed to adenomas (4 weeks) and

\section{A}
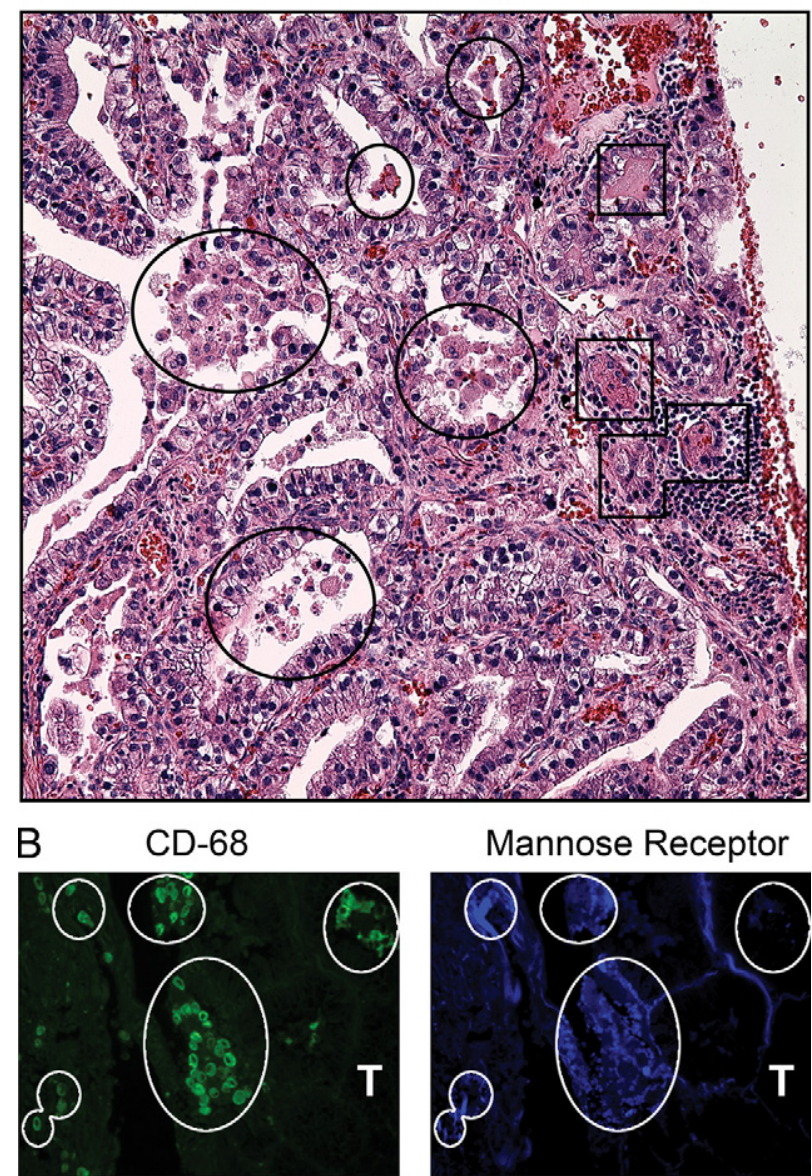

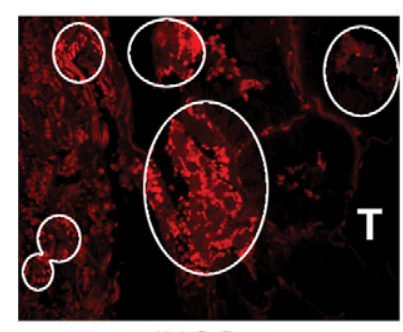

iNOS
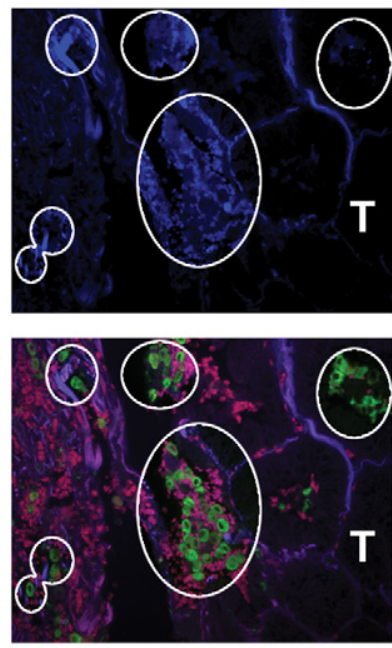

Co-localization
Figure 1. Activation state of macrophages associated with human AC. A H\&E-stained human ACs have both TAMs (circles) and TIMs (squares). B: Immunofluorescent staining for macrophages (green, CD-68) expressing both mannose receptor (blue) and iNOS (red). White circles indicate corresponding areas of macrophage localization. T indicates tumor tissue. Magnification for H\&E images is $\times 400$ and $\times 630$ for immunofluorescent staining 
Table 2. BAL Macrophage and BDMC Activation in Naïve and Tumor-Bearing Mice of Different Strains

\begin{tabular}{|c|c|c|c|c|c|}
\hline Strain & Carcinogenesis protocol & Time after carcinogen (wks) & Tumor multiplicity & Activation state & Tumor stage \\
\hline \multirow[t]{5}{*}{$A / J$} & Age-matched control & 24,42 & $0.0 \pm 0$ & $\operatorname{argl}^{\text {lowiNOS }}{ }^{\text {low }}$ & None \\
\hline & 1 Urethane & 24 & $24.5 \pm 0.8$ & $\operatorname{argl}^{\text {high }}{ }_{i N O S}{ }^{\text {low }}$ & Ad \\
\hline & & 42 & $49.8 \pm 4.8$ & argl $^{\text {lowiNOS }^{\text {high }}}$ & $A C$ \\
\hline & MCA/BHT & 24 & $84 \pm 6.0$ & argl $^{\text {highiNOSlow }}$ & Ad \\
\hline & & 42 & $N D$ & argl $^{\text {high }}$ iNOS $^{\text {low }}$ & $A C$ \\
\hline \multirow[t]{2}{*}{ FVB } & Age-matched control & 24 & $1.0 \pm 0.0$ & argl $^{\text {lowiNOS }}{ }^{\text {low }}$ & $\mathrm{Ad}$ \\
\hline & 1 Urethane & 24 & $10.8 \pm 2.8$ & $\operatorname{argl}^{\text {high }}{ }_{\text {iNOS }}{ }^{\text {low }}$ & Ad \\
\hline \multirow[t]{5}{*}{ BALB/cBy } & Age-matched control & 24,32 & $0.0 \pm 0$ & $\operatorname{argl}^{\text {highiNOS }}{ }^{\text {high }}$ & None \\
\hline & 7 Urethane & 24 & $17 \pm 5.0$ & $\operatorname{argl}^{\text {highiNOS }}{ }^{\text {high }}$ & Ad \\
\hline & & 32 & $25 \pm 1.9$ & $\operatorname{argl}^{\text {high }}$ NOS $^{\text {high }}$ & $A C$ \\
\hline & MCA/BHT & 24 & $33.5 \pm 9.0$ & $\operatorname{argl}^{\text {high }}{ }_{\text {iNOS }}{ }^{\text {low }}$ & Ad \\
\hline & & 32 & ND & argl $^{\text {highiNOSlow }}$ & $\mathrm{AC}$ \\
\hline \multirow[t]{5}{*}{ BALB/c } & Age-matched control & 24,32 & $0.0 \pm 0$ & argl lowiNOS low $^{\text {low }}$ & None \\
\hline & 7 Urethane & 24 & $29.7 \pm 3.1$ & argl $^{\text {high }}{ }_{\text {NNOS low }}$ & Ad \\
\hline & & 32 & $46.4 \pm 4.4$ & $\operatorname{argl}^{\text {high }}{ }_{i N O S}{ }^{\text {low }}$ & $A C$ \\
\hline & MCA/BHT & 24 & $5.9 \pm 1.6$ & argl $^{\text {highiNOS }}$ iow & $\mathrm{Ad}$ \\
\hline & & 32 & ND & $\operatorname{argl}^{\text {high }}{ }_{\text {iNOS }}{ }^{\text {low }}$ & $\mathrm{AC}$ \\
\hline \multirow[t]{5}{*}{ B6 } & Age-matched control & 24,42 & $0.0 \pm 0$ & $\operatorname{argl}^{\text {lowiNOS low }}$ & None \\
\hline & 1 Urethane & 24 & $0.86 \pm 0.2$ & $\operatorname{argl}^{\text {high }}{ }_{i N O S}{ }^{l o w}$ & Ad \\
\hline & & 42 & $4.6 \pm 0.6$ & argl $^{\text {highiNOS }}$ low & $\mathrm{Ad}$ \\
\hline & 7 Urethane & 24 & $8.7 \pm 2.2$ & $\operatorname{argl}^{\text {high }}{ }_{i N O S}{ }^{\text {low }}$ & $\mathrm{Ad}$ \\
\hline & & 42 & $13.0 \pm 0.1$ & $\operatorname{argl}^{\text {high }}{ }_{\text {iNOS }}{ }^{\text {low }}$ & Ad \\
\hline
\end{tabular}

ND indicates not determined; Ad, adenoma; AC, adenocarcinoma (these tumors invade adjacent tissue, are dysplastic, have high nuclear/cytoplasmic ratios, and are cellularly heterogenous ${ }^{48}$ ).

AC (8 weeks). These lesions completely regressed within 4 weeks of Dox withdrawal. Formalin-fixed lung sections from mice receiving Dox for 8 weeks and from mice receiving Dox for 8 weeks followed by Dox removal for 3 days, 7 days, or 4 weeks (4 mice per group) were examined by immunofluorescence for macrophage infiltration and polarization state as described above.

\section{FGF-10 Lung Tumor Model}

An FGF-10 transgene was ligated to the CCSP promoter and is expressed in bronchial nonciliated Clara cells. ${ }^{11}$ Conditional expression of the transgene is induced by exposure to Dox in drinking water. After 12 days of Dox exposure, spontaneous pulmonary tumors develop accompanied by a massive macrophage infiltration. When transgene expression is silenced, pulmonary tumors regress completely within 6 days, and the numbers of pulmonary macrophages decrease. ${ }^{11}$

\section{HT-29 Colon Cancer Xenograft Model}

To examine the activation state of pulmonary macrophages and BDMCs in a metastasis model, a luciferaseexpressing human colon cancer cell line HT-29 (Xenogen, Cranbury, NJ) was injected subcutaneously (s.c.; $1 \times 10^{6}$ cells in $200 \mu \mathrm{l}$ PBS) into the flanks of 8 male severe combined immunodeficient beige (SCID/bg) mice (Harlan Inc., Indianapolis, IN) to produce xenografts. ${ }^{40,41}$ Mice were housed in sterile microisolator cages and provided with sterile water and food ad libitum. Forty-six days after inoculation when solid tumors were $\sim 1.5 \mathrm{~cm}^{3}$, mice were sacrificed and their primary tumors, lungs, and bone marrow harvested and fixed. Lung metastases were observed in six of the eight mice upon histopathological and bioluminescence examination. Primary xenograft, formalin-fixed lungs, and BDMCs were characterized for macrophage infiltration and activation phenotypes as described above.

\section{Statistics}

Data are presented as means \pm SEM. Differences between conditions at specific time points were examined using Student unpaired $t$ test. One-way analysis of variance with Newman-Keuls post hoc analysis compared results from more than two groups, with $P<0.05$ considered significant.

\section{Results}

\section{Macrophages Exhibit Mannose} Receptor $^{\text {high }}$ iNOS $^{\text {high }}$ Staining in Human Pulmonary AC

In human lung cancer, the density of TAMs is inversely proportional to patient survival, implying their pathophysiologic significance. ${ }^{13}$ Macrophage polarization was examined in tissue sections of pulmonary AC from 14 different patients. Because of the abundance of arginase I in human lung epithelial tissue and its lack of up-regulation by IL-4 and IL-13 in human monocyte-derived macrophages, ${ }^{42,43}$ it is not a suitable marker for alternative/M2 polarization in human samples. Instead, we selected staining for mannose receptor as an indicator of M2 polarization, based on biomarkers identified in gene arrays. ${ }^{44}$ Each tissue section was analyzed by triple immunofluorescent imaging as well as H\&E staining. Figure $1, A$ and $B$, shows a representative human pulmonary 
AC. Tumor morphology varied, consisting of papillaryglandular or more solid growth patterns, and ranged from well- to poorly-differentiated. Both tumor infiltrating macrophages (TIMs) and TAMs were detected in each human sample. Despite morphological heterogeneity among the different AC sections, $100 \%$ of TIMs and TAMs exhibited mannose receptor (MRP) ${ }^{\text {high, indicating }}$ alternative polarization. Macrophages in distal uninvolved human lung may exhibit different polarization phenotypes, but these samples were not available for analysis. In 12 of the 14 tumors examined, TIMs and TAMs expressed MRP high ${ }^{\text {NOOS }}{ }^{\text {high }}$, indicating a mixed M1 + M2 polarization state.

\section{The Polarization Phenotype of Pulmonary Macrophages and BDMCs Is Dependent on Genetic Background and the Nature of the Carcinogen}

We have previously shown ${ }^{29}$ that all pulmonary macrophages are alternatively polarized during the adenoma stage of lung tumor development and classically polarized when these evolve into carcinomas in $\mathrm{A} / \mathrm{J}$ mice treated with a single injection of urethane. Because human lung TAMs and TIMs were MRPhighiNOS ${ }^{\text {high }}$, we examined additional models of chemically-induced lung tumors in several strains of mice. We determined macrophage phenotypes in both single agent carcinogenesis (urethane) and in a model of 2 stage carcinogenesis (MCA/BHT) wherein macrophage infiltration into the lungs augments tumor formation. ${ }^{32}$ In the following experiments, $100 \%$ of the macrophage population underwent the polarization changes indicated. BAL macrophage and BDMC polarization states were examined in five inbred strains with differing sensitivities to chemical carcinogens $(A / J>F V B>c B y>B A L B / C>B 6$, with $A / J$ mice being most sensitive) at various times after the initial urethane or MCA injection (Table 2). In more resistant strains (cBy, BALB/c and B6), multiple urethane injections are required to produce a substantial number of lung tumors. Resistant B6 mice receiving one or multiple urethane injections do not progress to malignancy by 42 weeks. All pulmonary macrophages and BDMCs prepared from naïve A/J, FVB, BALB/c, and B6 mice displayed an argl lowiNOS ${ }^{\text {low }}$ phenotype. In contrast, naïve cBy mice exhibited argl ${ }^{\text {high }}{ }^{\text {NNOS }}{ }^{\text {high }}$ expression in all BAL macrophages and BDMCs, constituting a mixed polarization phenotype (Table 2). cBy activation differs from that of the closely related BALB/c substrain, whose naïve myeloid polarization phenotype was argl ${ }^{\text {lowiNOS }}{ }^{\text {low. We }}$ estimated the magnitude of this substrain difference by the exposure times needed to detect immunofluorescent staining of iNOS and arginase I above background levels. By this semiquantitative technique, naïve cBy BAL macrophages contained more than three times as much arginase I ( $150 \mathrm{~ms}$ versus $580 \mathrm{~ms}$ ) and nearly eight times as much iNOS (311 ms versus 2010 ms) as did naïve BALB/c macrophages. When mice were treated with $\mathrm{MCA} / \mathrm{BHT}$, all strains examined exhibited argl ${ }^{\text {highiNOS }}{ }^{\text {low }}$ polarized TAMs and BDMCs throughout tumor development (Table 2).

Although various myeloid polarization states were observed after carcinogen exposure, arginase I was expressed in $100 \%$ of BAL macrophages and BDMCs detected in mice bearing benign lung tumors. Macrophages and BDMCs in highly resistant $\mathrm{B} 6$ mice $^{31,45}$ that had developed even a single lung tumor became argl $\left.\right|^{\text {high }}$ iNOS ${ }^{\text {low }}$, but pulmonary macrophages remained argl $^{\text {lowiNOS }}{ }^{\text {low }}$ in age-matched non-tumor-bearing controls. cBy mice maintain their naîve argl ${ }^{\text {highinOS }}{ }^{\text {high }}$ macrophage phenotype throughout urethane-induced carcinogenesis (as observed in human lung ACs, Figure 1), but when cBy mice were subjected to an MCA/ $\mathrm{BHT}$ carcinogenesis protocol, $100 \%$ of their BAL mac-
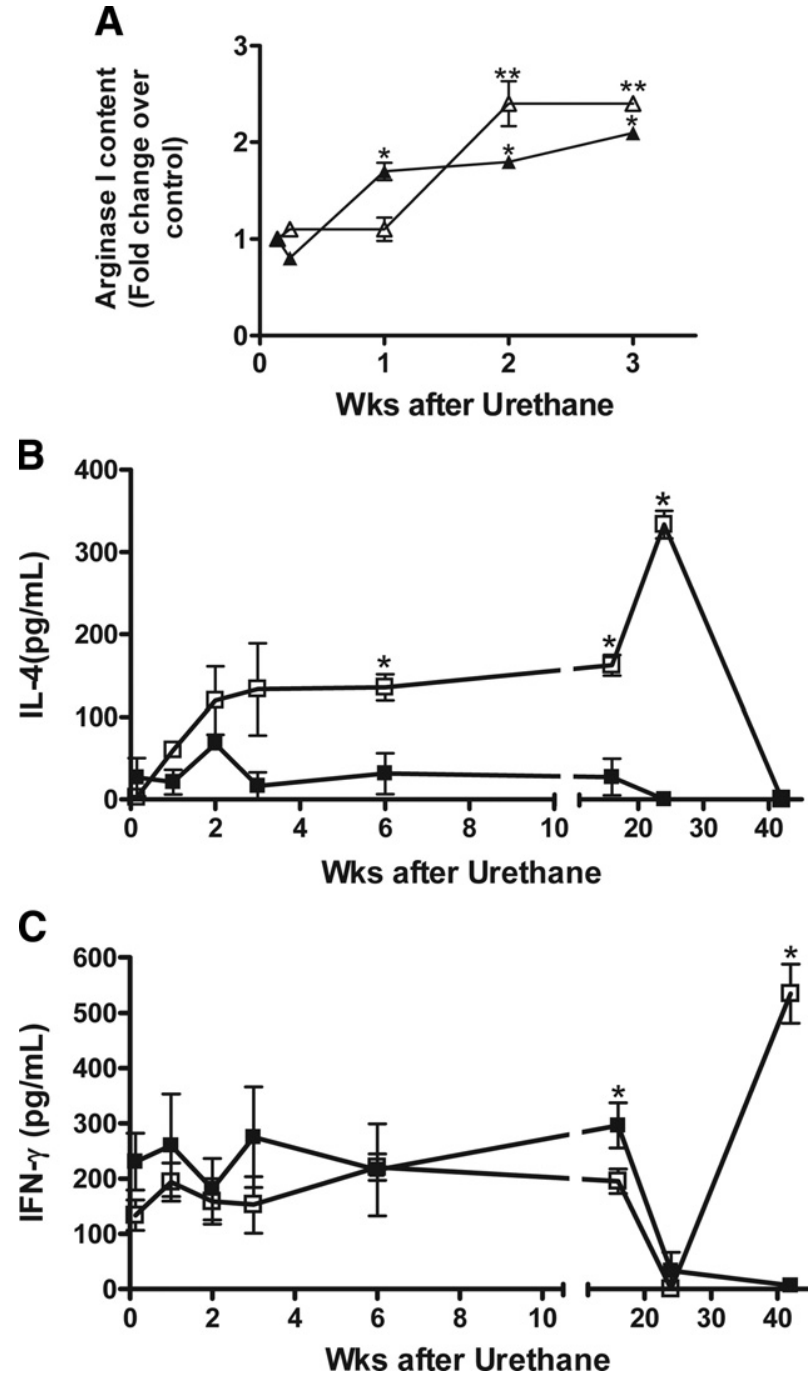

Figure 2. Time courses of macrophage activation and IL- 4 and IFN- $\gamma$ production in urethane-treated $\mathrm{A} / \mathrm{J}$ mice. BAL fluid, pulmonary macrophages and BDMCs were isolated from urethane treated $\mathrm{A} / \mathrm{J}$ mice at the indicated times. A: BAL macrophage (filled triangle) and BDMC (open triangle) polarization were examined by arginase I and iNOS immunofluorescence and compared with control naïve macrophage expression. ${ }^{*} P<0.05$ versus 1 day BAL macrophage, ${ }^{* * *} P<0.01$ versus 1 day BDMC. B: IL- 4 content in $\mathrm{BAL}$ from control (filled square) and urethane-treated (open square) A/J mice. ${ }^{*} P<0.05$ versus control. C: IFN- $\gamma$ expression in BAL from control (filled square) and urethane-treated (open square) A/J mice. ${ }^{*} P<0.05$ versus control. Cytokine content was assessed by ELISA. 
rophages and BDMCs switched to a predominantly argl highiNOS $^{\text {low }}$ phenotype, showing that classical macrophage polarization is both strain and carcinogen dependent.

Quantitative analysis of pulmonary macrophage infiltration and changes in the bone marrow macrophage populations were examined. The extent of BAL macrophage infiltration in $\mathrm{A} / \mathrm{J}, \mathrm{cBy}$, and $\mathrm{B} 6$ mice reflects the relative lung tumor susceptibilities of these strains, but the number of resident bone marrow macrophages does not correlate with these strain-dependent variations (Supplemental Figure S1, available online at http://ajp.amjpathol.org).

\section{Alveolar Macrophage and BDMC Polarization Occurs Early in Tumor Development}

Pulmonary macrophage populations in $\mathrm{A} / \mathrm{J}$ mice changed from argl ${ }^{\text {lowiNOS }}{ }^{\text {low }}$ in naïve mice to an argl ${ }^{\text {high }}$ iNOS ${ }^{\text {low }}$ state 24 weeks after carcinogen exposure. ${ }^{29}$ To determine how early during neoplastic progression pulmonary tumors influence macrophage and monocyte polarization, BAL macrophages and BDMCs were isolated from urethanetreated and age-matched control mice 1, 2, 7, 14, and 21 days after carcinogen exposure. BAL macrophages remained argl ${ }^{\text {lowiNOS }}{ }^{\text {low }}$ up to 7 days after urethane treatment (Figure 2A). Because urethane is rapidly metabolized and cleared within 24 hours of administration into mice, ${ }^{46}$ macrophages were not directly activated by the carcinogen per se or any of its distal metabolites. By seven days after urethane exposure, expression of arginase I increased in all BAL macrophages, whereas iNOS expression was undetectable by immunofluorescence staining (Supplemental Figure S2A, available online at http://ajp.amjpathol.org). This alternative polarization was consistent within the entire population of pulmonary macrophages.

The BDMC population expressed no arginase or iNOS until 14 days after urethane exposure when their arginase I expression increased 2.4-fold compared with controls; again, no iNOS expression was detected, analogous to the pulmonary macrophages (Figure 2, Supplemental Figure S2B, available online at http://ajp.amjpathol.org). This delay in BDMC polarization suggests that resident pulmonary macrophages respond to local signals emanating from early pulmonary lesions. The increased arginase I expression in BDMCs one week later implies that signals emitted by these early lesions or the already polarized pulmonary macrophages were systemically transported to the bone marrow to activate BDMCs. IFN- $\gamma$ induces M1 polarization, whereas a mixture of IL-4 and $\mathrm{IL}-13$ induces M2 polarization. ${ }^{17}$ Thus, IFN- $\gamma$ and IL-4 cytokine contents were examined in lavage fluid from these mice. IL-4 and IFN- $\gamma$ secretion into BAL fluid corresponded with the timing of argl $^{\text {high }}{ }_{\text {iNOS }}{ }^{\text {low }}$ and argl $^{\text {lowiNOS }}{ }^{\text {high }} \mathrm{BAL}$ macrophage polarization, respectively (Figure 2, B and $\mathrm{C}$, respectively). Pre-neoplastic lesions are thus capable of altering both the local microenvironment and can systemically influence macrophage populations in distant organs.
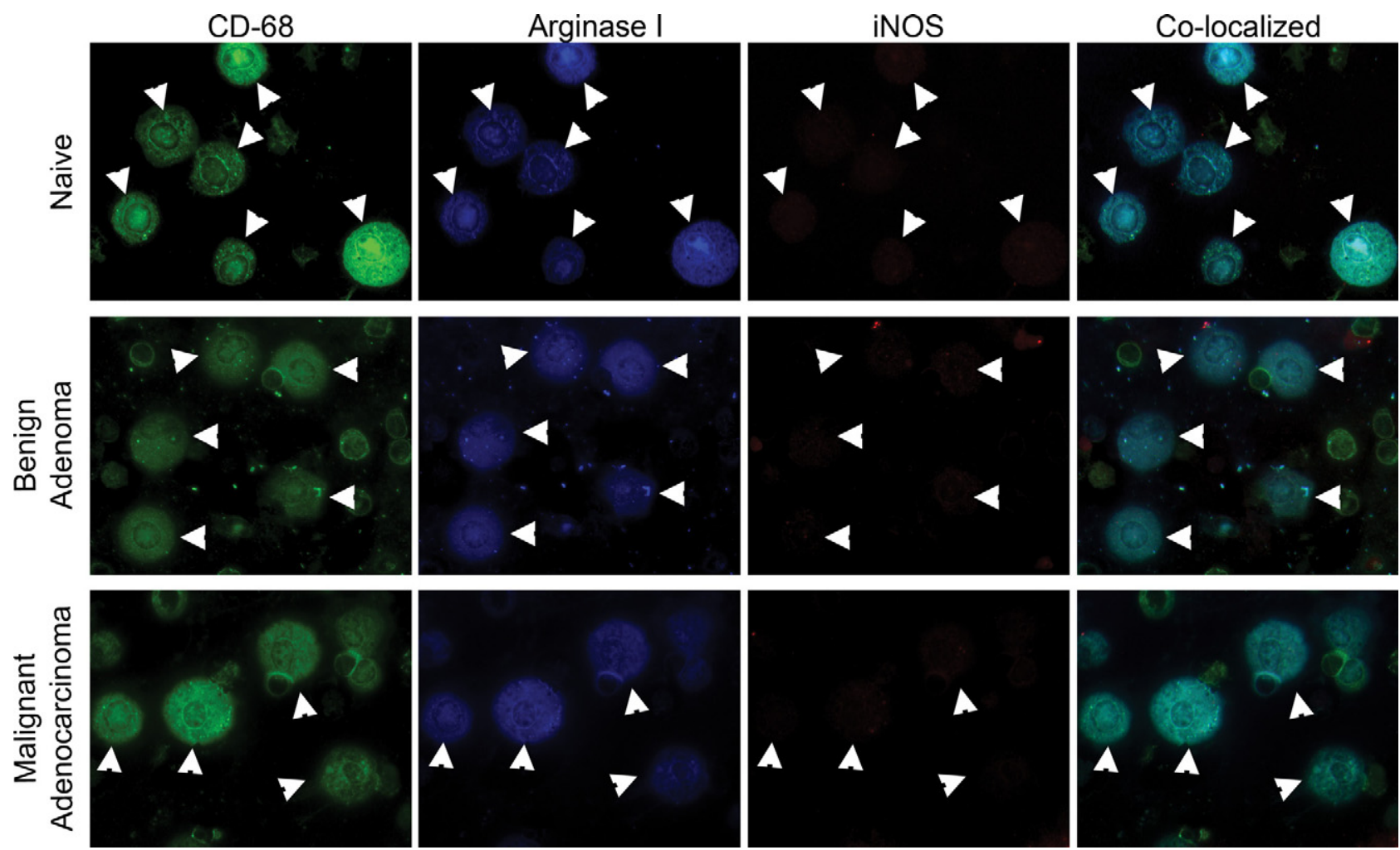

Figure 3. Peritoneal macrophages (indicated by white arrowheads) in urethane-treated A/J mice. Peritoneal macrophages (CD-68, green) from naïve A/J mice and mice with benign ( 24 weeks after urethane) and malignant ( 42 weeks after urethane) lung tumors express arginase I (blue) but not iNOS (red). Magnification $\times 630$. 
Polarization of Monocytes/Macrophages Is Specific to the Tumor-Bearing Organ and Bone Marrow

Because BDMCs were polarized after pulmonary macrophage polarization, we examined whether monocyte/ macrophage pools in other extra-pulmonary organs were similarly affected. Peritoneal macrophages were isolated from naïve and tumor bearing A/J mice 24 and 42 weeks after urethane administration and assayed for arginase I and iNOS expression (Figure 3). All peritoneal macrophages were argl ${ }^{\text {high }}$ iNOS $^{\text {low }}$ both in naïve mice and throughout pulmonary tumor development, even though pulmonary macrophages and BDMCs in naïve mice were argl ${ }^{\text {lowiNOS }}{ }^{\text {low }}$ and changed from argl $^{\text {highiNOS }}{ }^{\text {low }}$ to argl $^{\text {lowiNOS }}{ }^{\text {high }}$ by 42 weeks after urethane (Table 2). Thus, polarized BDMCs specifically infiltrate tumor-bearing lungs and either do not infiltrate into the peritoneal

A
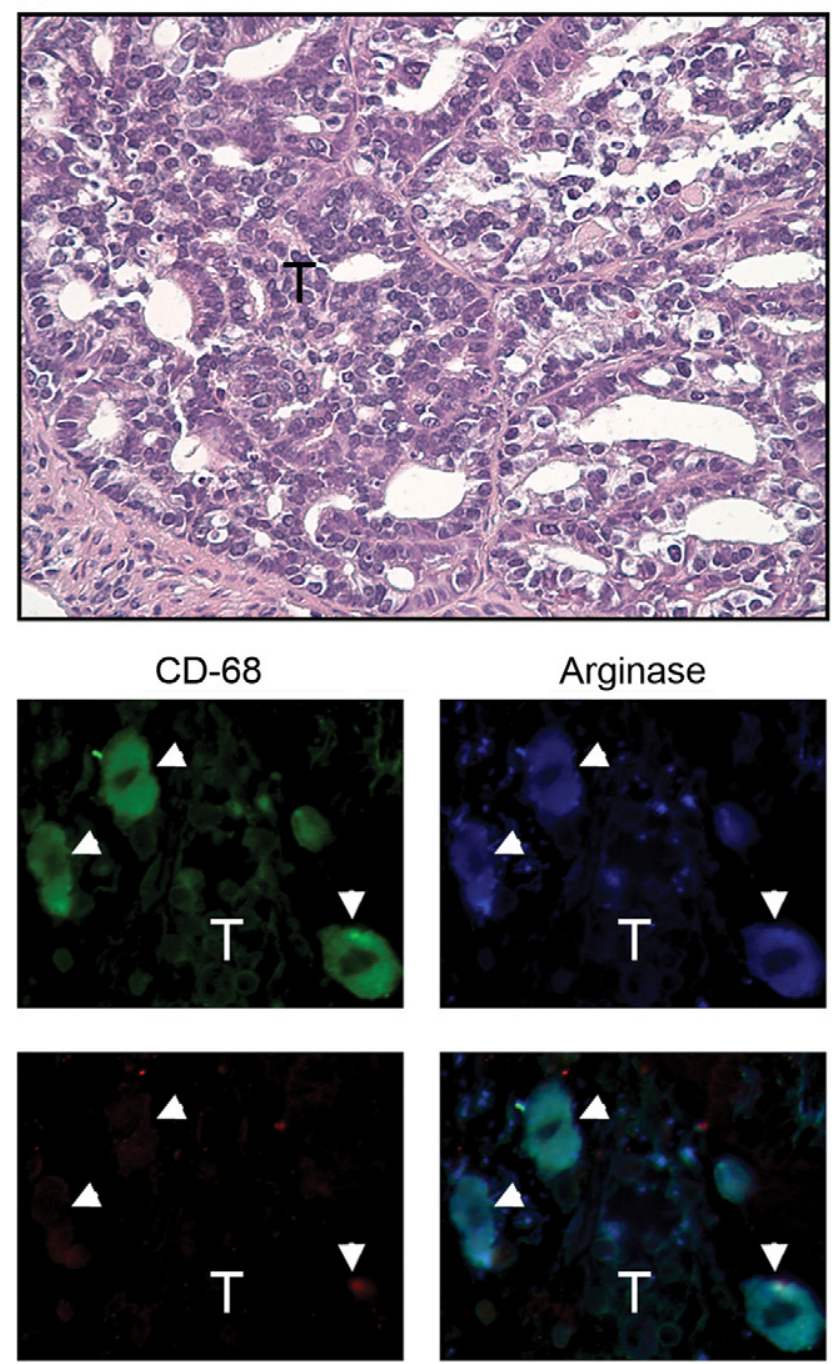

iNOS

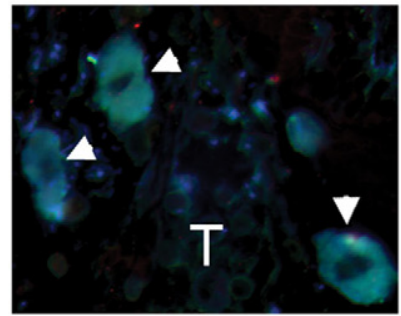

Co-localization
B
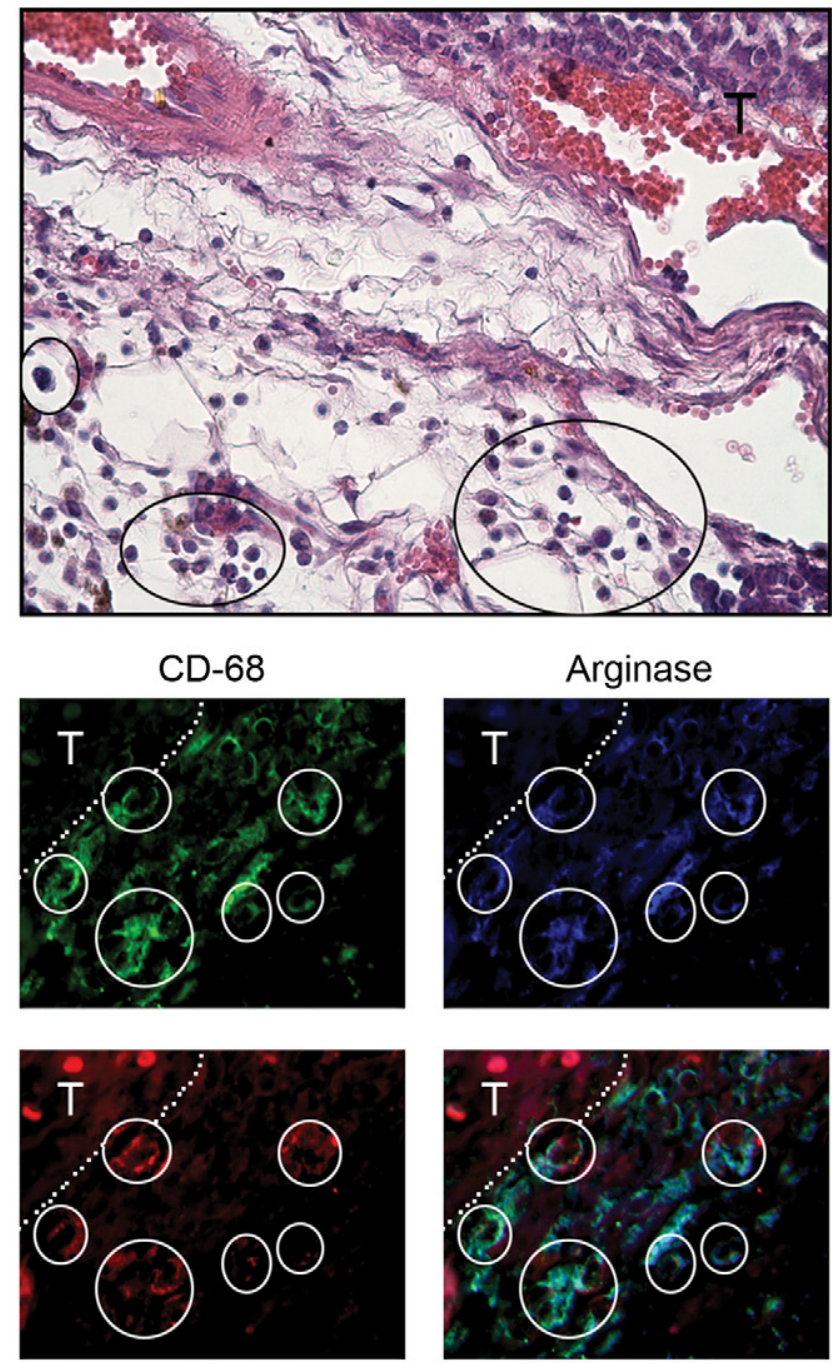

iNOS
Arginase
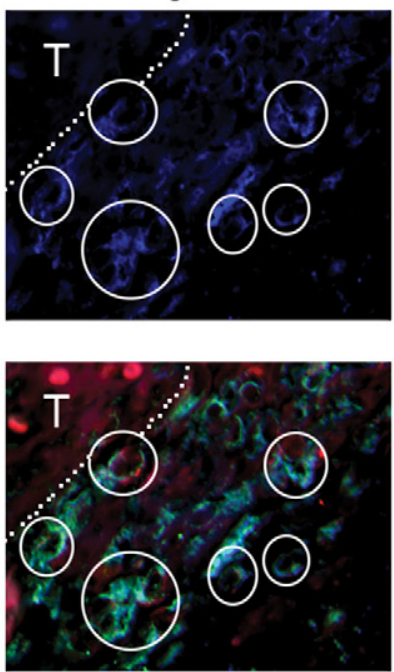

Co-localization

Figure 4. TAM activation in a primary murine model of prostate cancer. A: H\&E sections show a moderately-differentiated prostate tumor (T). TAMs, indicated by white arrowheads (CD-68, green) express arginase I (blue) but not iNOS during early tumor progression. B: Tissue adjacent to a late stage, poorlydifferentiated prostate tumor showing TAMs (black circles) stained by H\&E. These macrophages (green) express both iNOS (red) and arginase I (blue). White circles denote corresponding areas of macrophage localization. 
TAMs surrounding PIN were $\arg ^{\text {high }}$ iNOS $^{\text {low }}$, indicating M2 polarization (data not shown), as were macrophages from well-differentiated and moderately differentiated prostate ACs (Figure 4A). All macrophages associated with advanced poorly differentiated prostatic ACs were arg $^{h^{\text {high }}}$ iNOS $^{\text {high }}$ (mixed M1 + M2 polarization; Figure 4B). Macrophage expression of iNOS in late-stage cancer was also demonstrated in the urethane-induced pulmonary ACs in A/J mice, ${ }^{29}$ urethane-induced ACs in cBy mice (Table 2), and TIMs and TAMs in human pulmonary AC (Figure 1).

\section{Macrophage Polarization Returns to an arglow/iNOS $^{\text {low }}$ State upon Resolution of Pulmonary Tumors}

Pulmonary macrophages were examined in two reversible genetic models of pulmonary cancer during tumor development and after tumors had regressed to examine macrophage polarization in a non-carcinogen-induced lung tumor model and determine whether tumor regression affects macrophage polarization. In the first model, tumors were induced by overexpressing human KRAS (mutated in codon 12 from $G$ to D) under the control of the CCSP promoter in FVB mice. This specifically targets mutant transgene expression to bronchiolar Clara cells and alveolar type II cells with administration of Dox in drinking water. When Dox is removed, the mutated on- cogene is not expressed, and tumors regress rapidly. ${ }^{46}$ In this model, macrophages not only localize outside the mutant KRAS-induced tumor parenchyma as observed after chemical carcinogenesis but are also found within the tumor as $\mathrm{TIMS}^{46}$ similar to that seen in human lung AC. Seven days after Dox administration, pulmonary lesions appear. ${ }^{39}$ By 2 months after Dox exposure, adenomas with both TAMs and TIMs are apparent in H\&Estained sections (Figure 5A). All BDMCs and pulmonary macrophages in naïve FVB mice are argl lowiNOS ${ }^{\text {low }}$ (Table 2), whereas $100 \%$ of TAMs and TIMs from this strain express argl $^{\text {high }}{ }_{\text {iNOS }}{ }^{\text {low }}$, indicating alternative polarization (Figure 5A). Three days after Dox was removed from the drinking water, tumors began to regress, but as long as small yet detectable tumor remnants remained, 100\% of macrophages were argl $\mathrm{I}^{\text {highiNOS }}{ }^{\text {low }}$. Seven days after Dox removal, small hyperplastic lesions and TAMs remained in the lungs but TIMs had disappeared (Figure $5 B$ ). One month after Dox removal when lungs are tumorfree and histologically normal, all pulmonary macrophages returned to an argl lowiNOS $^{\text {low }}$ polarization state (Figure 5C), demonstrating that the presence of the tumor is necessary to maintain polarization state changes. Macrophage argl ${ }^{\text {high }}$ iNOS $^{\text {low }}$ polarization was also demonstrated in FVB mice that develop lung tumors when the FGF10 transgene is induced by Dox ${ }^{11}$ (see Supplemental Figure S3, available online at http://ajp.amjpathol.org). Analogous to the conditional mutant KRAS model, when
A

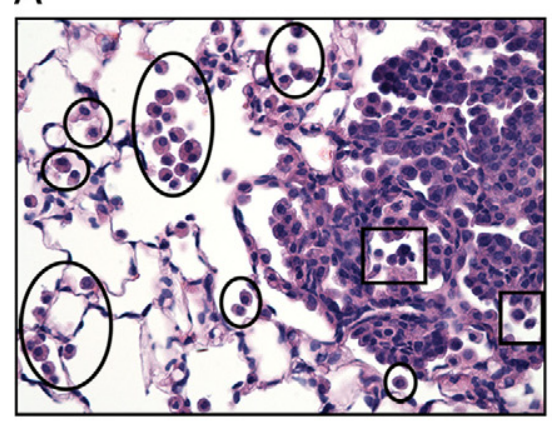

$\mathrm{F} 4 / 80$
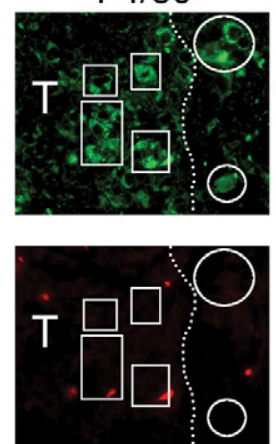

iNOS
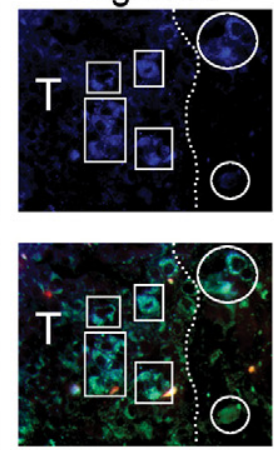

Co-localization
B

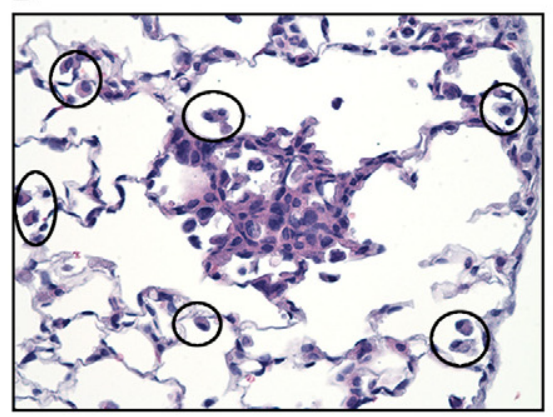

$\mathrm{F} 4 / 80$

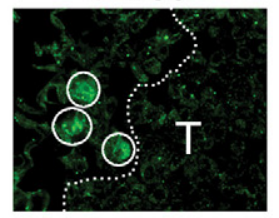

Arginase I

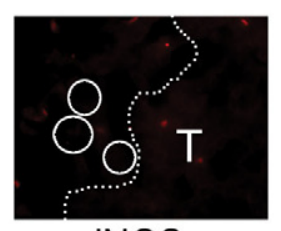

iNOS
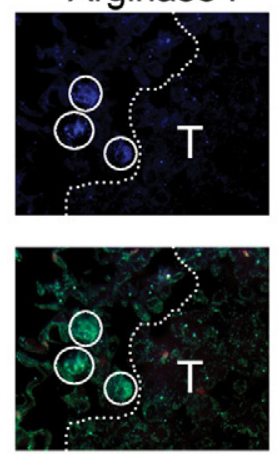

Co-localization
C
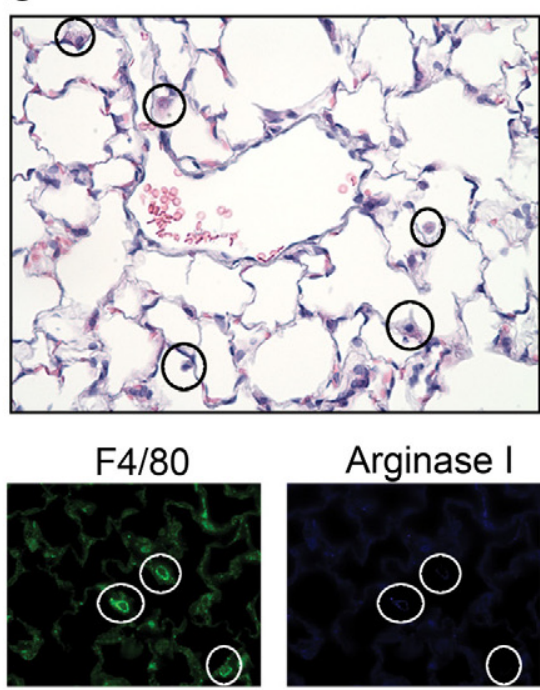

Arginase I
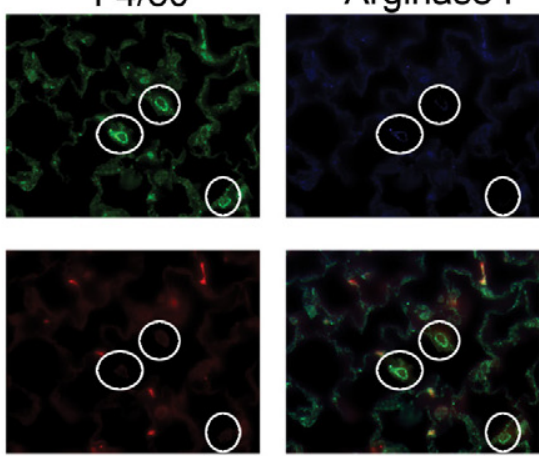

iNOS

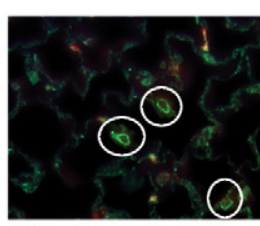

Co-localization

Figure 5. Pulmonary macrophage activation in a mutant Kras transgenic lung cancer model. Conditional overexpression of mutant Kras induces pulmonary tumors. A: Two months after DOX treatment, H\&E images show the location of macrophages peripheral to, TAMs (circles), and within, TIMs (squares), pulmonary tumors ( $\mathrm{T}$, border indicated by white dashed line). Macrophages identified with F4/80 (green) also stain for arginase I (blue) but not iNOS (red). B: Seven days after DOX removal, H\&E staining indicates lesions and associated macrophages (circles) are still present in the lungs. TAMs express arginase 1 (blue). C: One month after DOX removal, tumors have regressed. Pulmonary macrophages (circles) expressed neither arginase I nor iNOS. Magnification $\times 630$ for fluorescent images, $\times 400$ for H\&E images. 
A

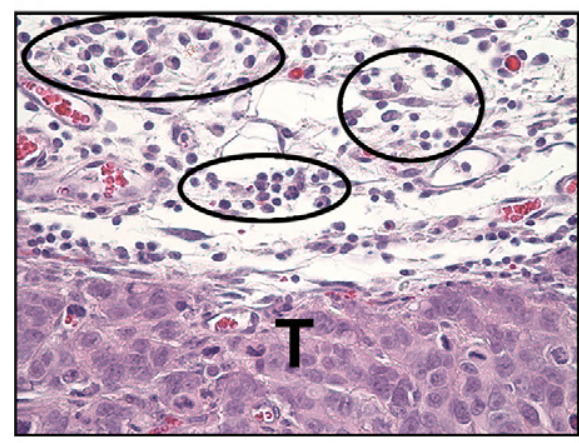

C

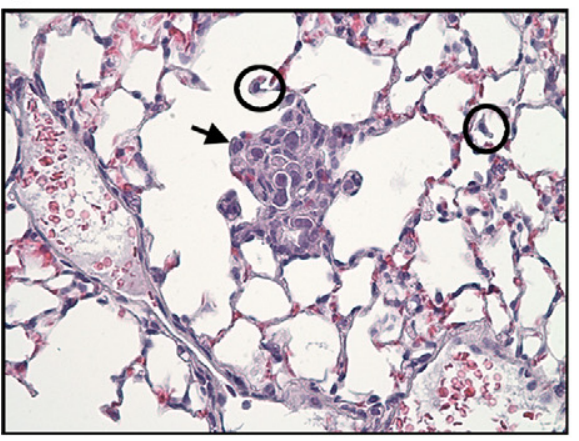

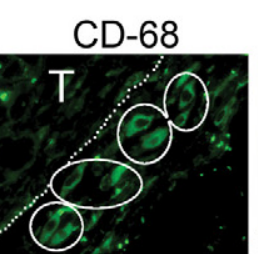

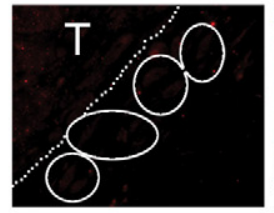

iNOS

$\mathrm{F} 4 / 80$
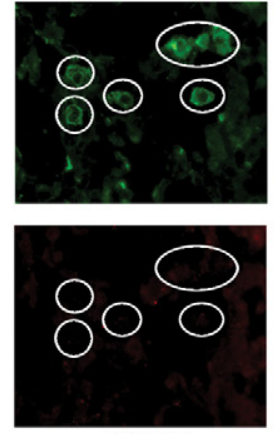

iNOS
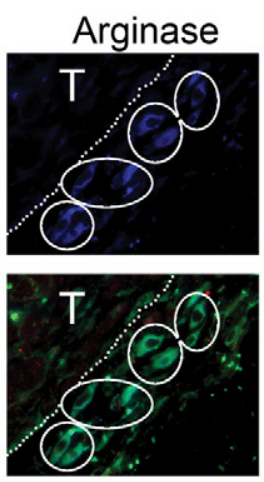

Co-localization
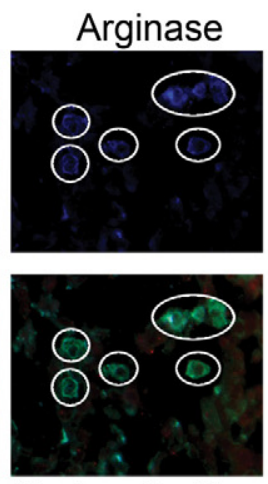

Co-localization
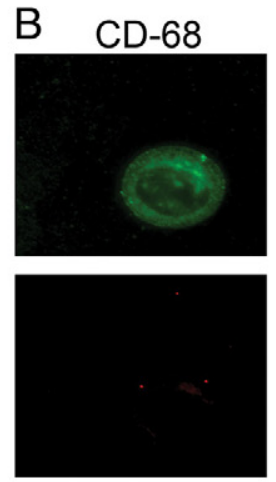

iNOS
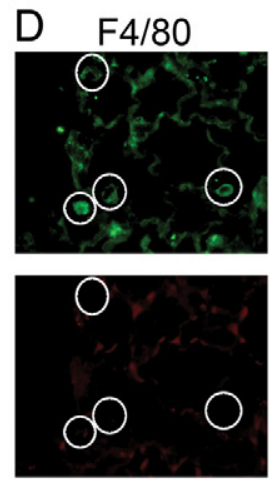

iNOS
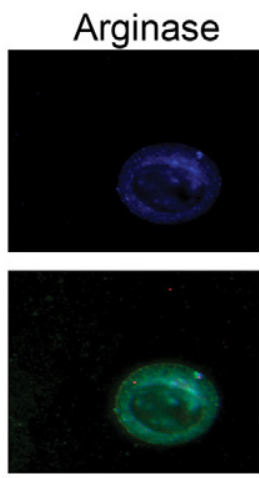

Co-localization

Arginase
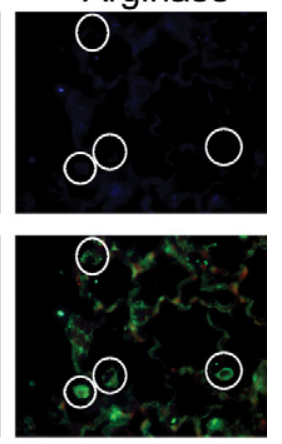

Co-localization

Figure 6. Activation status of macrophages in a human HT-29 colon cancer xenograft model. Macrophages and BDMCs are identified with anti-F4/80 or anti-CD-68 respectively (green). A: H\&E staining shows that macrophages (black circles) surrounding the xenograft (T) express arginase I (blue) but not iNOS. White circles indicate areas of macrophage localization. B: BDMCs (green) isolated from xenograft-bearing mice express arginase I (blue) but not iNOS. C: H\&E section shows pulmonary macrophages (black circles) in lungs containing HT-29 metastases (black arrow). Macrophages positively stain for arginase I (blue) but not iNOS. White circles indicate areas of macrophage localization. D: Pulmonary macrophages (green, white circles) in lungs with no detectable metastases stain for neither arginase-I nor iNOS. Magnification $\times 630$ for fluorescent images, $\times 400$ for H\&E images.

expression of the FGF10 transgene was turned off, tumors regressed and macrophage polarization returned to argl ${ }^{\text {lowiNOS }}{ }^{\text {low }}$.

\section{Pulmonary Macrophage Polarization Occurs Only after Tumor Metastasis to the Lungs in a Xenograft Model of Human Colon Cancer}

A human xenograft colon cancer model allowed us to examine the contribution of pulmonary metastasis to macrophage activation and confirm tumor to marrow signaling in an extra-pulmonary cancer model. HT-29 human colon cancer cells can metastasize from their primary site of implantation to the lungs within 46 days after injection into the flank. ${ }^{40,41}$ We analyzed macrophage/ monocyte activation in three different microenvironments in this model, macrophages associated with the primary implant (TAMs), macrophages associated with metastatic colon cancer deposits in the lungs, and BDMCs from animals with primary and metastatic tumors. All macrophages located in the stroma surrounding the primary xenograft were argl ${ }^{\text {high }}$ iNOS $^{\text {low }}$, indicating M2 TAM activation (Figure 6A). Consistent with the concept of tumor to marrow signaling, all BDMCs from mice with HT-29 flank tumors were also argl ${ }^{\text {highiNOS }}{ }^{\text {low }}$ (Figure 6B). Alternative activation of BDMCs was not dependent on the presence of tumor tissue in lungs, because this occurred both in mice where lung metastases had developed as well as mice with no detectable metastases. Metastasis of HT-29 cells to the lungs occurred in six of eight mice, as determined by serially sectioning fixed lung tissue. All pulmonary macrophages from lungs containing HT-29-derived metastases were argl ${ }^{\text {high }}$ NOS low, regardless of their proximity to metastatic deposits (Figure 6C). However, the polarization state of pulmonary macrophages in the two mice lacking detectable lung metastases remained argl lowiNOS low (Figure 6D), indicating that pulmonary macrophage polarization required the local presence of these colon cancer metastases.

\section{Discussion}

We demonstrate herein that TAMs and BDMCs express arginase I, thus indicating alternative polarization during tumor formation regardless of organ site (lung, flank, or prostate) or carcinogen (see Figure 7). This is an early event, occurring before chemically-induced tumors can be detected macroscopically. In some models (human NSCLC, A/J mice treated with urethane, cBy mice treated with urethane, and the TRAMP prostate cancer model) iNOS ${ }^{\text {high }}$ polarization of TAMs, 
1. Primary tumors influence macrophage activation

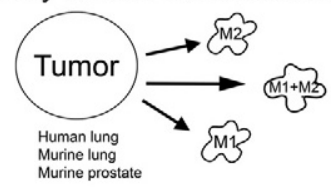

2. Primary lung tumors: BDMC's mimic TAMs

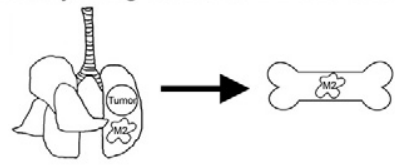

3. Xenograft tumor: BDMC's and metastatic lesion associated macrophages mimic TAMs
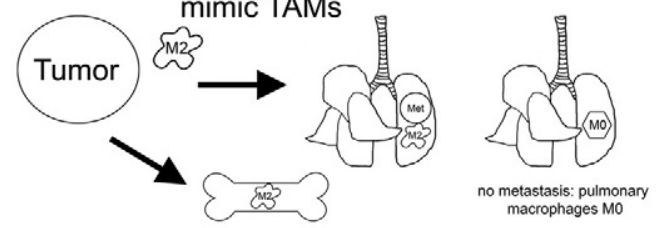

4. Transgenic pulmonary tumors: TAM activation dependent upon presence of tumor

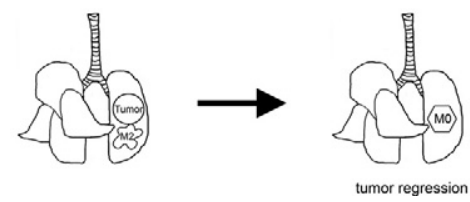

Figure 7. Schematic summarizing macrophage activation in mouse models of lung cancer, prostate cancer, tumor regression, and metastasis.

TIMs, and BDMCs also occurs in late-stage disease. These dynamic changes in monocyte/macrophage polarization are unique to TAMs and BDMCs, as peritoneal macrophages were not differentially polarized in response to lung tumor formation or progression. In genetic models in which lung tumors regress, pulmonary macrophages return to an argl ${ }^{\text {lowiNOS }}{ }^{\text {low }}$ phenotype. When BDMCs are polarized in response to a flank tumor, pulmonary macrophages remain arglow iNOS ${ }^{\text {low }}$ unless tumor cells detach and metastasize to the lung.

Analysis of pulmonary macrophages from urethanetreated $\mathrm{A} / \mathrm{J}$ mice indicates that macrophage polarization is a very early event in lung cancer, presumably supporting and maintaining tumor development. A time course after urethane administration to $\mathrm{A} / \mathrm{J}$ mice revealed argl ${ }^{\text {highiNOS }}{ }^{\text {low }}$ polarization as early as 1 week after urethane, when microscopic tumors (referred to as microadenomas ${ }^{47}$ or atypical adenomatous hyperpla$\operatorname{sias}^{48}$ ) are developing. Because TAMs were not polarized before this time, macrophage polarization is not a direct consequence of urethane itself or any of its rapidly cleared metabolites. Polarization of BDMCs occurs soon after pulmonary macrophage polarization in this model. Although macrophage polarization changed very early in lung neoplasia, the number of macrophages in the lungs did not increase significantly within the first 24 weeks after urethane treatment, implying that even though BDMCs were polarized, they were not actively recruited to the lungs until many weeks later. BMDC polarization is not limited to a response to pulmonary tumorigenesis because BDMCs were also polarized by the growth of a colon tumor xenograft. Detection of polarized BDMCs in the circulation may thus imply the presence of neoplastic lesions but not their anatomical source.

The exquisite sensitivity of the macrophage response to pulmonary neoplasia is illustrated by argl ${ }^{\text {high }}$ iNOS low polarization in resistant $\mathrm{B} 6$ mice ${ }^{31,45}$ given a single injection of urethane so that only a small percentage develop lung tumors. BAL macrophages remained arglowiNOS low in the mice that did not develop tumors, whereas pulmonary macrophages in mice with even one lung tumor expressed arginase I. Because macrophage infiltration has been shown to be a necessary component of BHTmediated lung tumor promotion, we also examined macrophage activation in mice treated with $\mathrm{MCA}+\mathrm{BHT}$. Argl ${ }^{\text {lowiNOS }}{ }^{\text {low }}$ to argl $^{\text {highiNOS }}{ }^{\text {low }}$ polarization in pulmonary adenoma-bearing mice was also observed in this model. Unlike TAMs associated with urethane-induced lung tumors in A/J mice, TAMs associated with tumors induced by $\mathrm{MCA}+\mathrm{BHT}$ or urethane in other strains did not switch to argl $^{\text {lowiNOS }}{ }^{\text {high }}$ polarization when tumors progressed to AC, but remained argl I $^{\text {igh }}$ iNOS $^{\text {low }}$ throughout AC development. Macrophages isolated from naïve mice are tumoricidal but can be made ten times more potent at killing tumor cells after M1 polarization with IFN- $\gamma,{ }^{49}$ consonant with their classical role in host defense. Elevated arginase expression in M2 macrophages reduces the amount of $\mathrm{NO}$ available to kill tumor cells, ${ }^{49}$ inhibits antigen presentation, ${ }^{21}$ and enhances the capacity of myeloid suppressor cells to inhibit T cell proliferation. ${ }^{50}$ Polyamines secreted by M2 macrophages encourage tumor cell growth in vitro, while inhibiting arginase activity reduces tumor growth in vivo. ${ }^{51}$ Cytokines such as TNF- $\alpha, \mathrm{IL}-1 \beta$, and IL-6 released by M2 macrophages enhance tumor cell survival. ${ }^{52}$ Hence, the association of M1 TAMs with $A C$ would in theory cause tumor cell death, yet $A C s$ in $A / J$ mice are not destroyed by the M1 polarized TAMs that surround them. A/J macrophages are defective in their ability to become tumoricidal both in vitro and in vivo, possibly accounting for this apparent discrepancy. ${ }^{53-55}$

The cBy substrain of BALB mice also exhibited an exception to the trend of argl $^{\text {low }}{ }^{\text {NOSOS }}{ }^{\text {low }}$ to argl ${ }^{\text {highiNOS }}{ }^{\text {low }}$ polarization of TAMs in early tumorigenesis. BDMCs and BAL macrophages from naïve cBy mice were argl ${ }^{\text {highiNOS }}{ }^{\text {high }}$, a mixed $\mathrm{M} 1+\mathrm{M} 2$ phenotype that persists in macrophages associated with both benign and malignant tumors induced by multiple urethane injections. In contrast, TAMs in cBy mice exposed to MCA/BHT carcinogenesis express argl high iNOS ${ }^{\text {low }}$ throughout tumor development, showing that TAM polarization is a consequence of both genetic background and tumor etiology. The mixed argl high iNOS ${ }^{\text {high }}$ macrophage polarization in this strain is similar to that seen in human pulmonary $A C$ and late stage murine prostate tumors (Figures 1 and 4).

Strain-dependent variations in the degree of macrophage infiltration during lung neoplasia do not arise from the genetic differences among strains in the number of 
bone marrow macrophages (Supplemental Figure S1, available online at $h t t p: / / a j p . a m j p a t h o l . o r g)$. These differences may reflect strain-dependent variations in the amount or kinds of chemokines secreted by TAMs that recruit BDMCs to the lungs or in the relative sensitivities of these BDMCs to such chemoattractants. We have shown previously ${ }^{56}$ that $\mathrm{BHT}$ induces lung epithelial cells to produce one such macrophage chemoattractant, CCL2, a few days before macrophages enter the lungs. Whether $\mathrm{A} / \mathrm{J}, \mathrm{cBy}$, or B6 mice vary in chemokine production, expression of the relevant chemokine receptor, or downstream signaling after chemokine binding to receptors is not known. Because both $\mathrm{A} / \mathrm{J}$ and B6 BDMCs in adenoma-bearing mice are argl ${ }^{\text {high }}$ iNOS ${ }^{\text {low }}$ polarized while showing great disparity in the degree of lung infiltration by macrophages, those signals that polarize BDMCs presumably are different from recruitment signals.

Tumor to marrow signaling is not limited to murine cancers, because HT-29 colon tumor cells injected into immuno-compromised SCID mice induce arg $^{\text {high }}$ iNOS $^{\text {low }}$ polarization in both TAMs associated with the growing xenograft and BDMCs. In those mice in which colon tumor cells metastasized to the lungs, pulmonary macrophages were also argl ${ }^{\text {high }}{ }^{\text {NNOS }}{ }^{\text {low. }}$. Pulmonary macrophages remained argl ${ }^{\text {low }}$ iNOS ${ }^{\text {low }}$ in mice without detectable HT-29 pulmonary metastases, indicating local signaling by metastatic lesions. Tumor cells exert local changes on macrophages co-cultured with human ovarian cancer cells, ${ }^{28}$ as is indicated by the appearance of arg $^{\text {high }}{ }^{\text {iNOS }}{ }^{\text {low }}$ pulmonary macrophages in lungs of urethane-treated $\mathrm{A} / \mathrm{J}$ mice one week before argl ${ }^{\text {highiNOS }}$ low BDMCs are detectable. Because SCID mice lack mature $\mathrm{B}$ and $\mathrm{T}$ cells, we deduce that the argl ${ }^{\mathrm{low}} \mathrm{NNOS}^{\mathrm{low}}$ to arg $^{\text {high }}{ }^{\text {iNOS }}{ }^{\text {low }}$ switch can occur without involvement of $\mathrm{T}_{\mathrm{H}} 2$ cytokine production from pulmonary $\mathrm{T}$-cells. The source of activating IFN- $\gamma$ and IL-4 cytokines found in BAL from tumor-bearing lungs was not determined, but this study suggests that cells other than lymphocytes may produce sufficient amounts to polarize both local macrophages and distal BDMCs. Whether production of these cytokines is muted in SCID mice compared with immuno-competent mice has not been determined but is of interest if manipulation of innate or adaptive immunity is used to treat cancer.

ArgllowiNOS ${ }^{\text {low }}$ to Argl $^{\text {high }}$ iNOS ${ }^{\text {low }}$ polarization was also observed in TAMs from lungs bearing tumors induced by overexpressing mutant $\mathrm{Kras}^{38}$ or wild-type $\mathrm{FGF}-10^{10}$ in Clara and type 2 cells. Conditional overexpression of either transgene was accompanied by arg ${ }^{\text {highiNOS low }}$ expression in pulmonary macrophages even though neoplastic growth is greatly accelerated compared with chemically-induced tumorigenesis. Thus, whether tumors appear within days (genetic models) or weeks (chemical carcinogenesis), early lung neoplasia is associated with alternative polarization of macrophages. When tumors induced by either transgene were allowed to regress by halting transgene transcription, the pulmonary macrophage population reverted back to argl lowiNOS low. As long as even tiny lesions remained before complete tumor regression was achieved, macrophages continued to be alternatively polarized. Macrophage polarization thus accompanies lung tumor growth when KRAS is the only epithelial mutation, or in the case of FGF-10 overexpression, when tumors appear in the absence of any known epithelial mutation. We confirmed that macrophages infiltrate the parenchyma of $K$-Ras $4 b+{ }^{G 12 D}$-induced lung tumors, as was originally reported. ${ }^{39}$ This differs from other mouse lung tumor models where macrophages remain adjacent to, but outside of, the tumor parenchyma, but is similar to human lung cancer where TIMs are detected. Both TIMs and TAMs detected in this transgenic mutant KRAS model are argl ${ }^{\text {highiNOS low }}$, whereas TIMs and TAMs associated with human lung cancer are argl $\left.\right|^{\text {highiNOS }}{ }^{\text {high }}$. Although TIMs and TAMs vary in other molecular characteristics, such as the relative contents of adhesion molecules that allow TIMs to cross the tumor vasculature or the up-regulation of IL-10 synthesis that has been reported to occur only in TAMs, ${ }^{57}$ they display similar activation phenotypes.

Polarization of TAMs to an alternatively activated phenotype, first described by Mills, ${ }^{17,58}$ Mantovani, ${ }^{59}$ and their colleagues, ${ }^{12}$ has been demonstrated in several human cancers and experimental mouse models. TAMs, however, can be classically or alternatively activated or exhibit a mixed M1 + M2 phenotype. ${ }^{52}$ In this study, primary mouse lung and prostate tumors, as well as human xenograft tumors, are surrounded by polarized TAMs. It remains to be clarified how tumor cells and macrophages co-evolve to favor tumor progression. ${ }^{60} \mathrm{~A}$ thorough understanding would refine therapeutic targeting to the tumor microenvironment that could be used as an adjuvant along with standard cytotoxic interventions directed at solid carcinomas.

\section{Acknowledgment}

We are grateful to Dr. Jeffrey A. Whitsett (University of Cincinnati Children's Hospital Medical Center) for the kind gift of FGF10tg lung sections.

\section{References}

1. Nathan C: Points of control in inflammation. Nature 2002, 420 846-852

2. Coussens LM, Werb Z: Inflammation and cancer. Nature 2002 , 420:860-867

3. Geissmann F, Jung S, Littman DR: Blood monocytes consist of two principal subsets with distinct migratory properties. Immunity 2003, 19:71-82

4. Malkinson AM: Role of inflammation in mouse lung tumorigenesis: a review. Exp Lung Res 2005, 31:57-82

5. Balkwill F, Mantovani A: Inflammation and cancer: back to Virchow? Lancet 2001, 357:539-545

6. Williams CS, Goldman AP, Sheng H, Morrow JD, Dubois RN: Sulindac sulfide, but not sulindac sulfone, inhibits colorectal cancer growth. Neoplasia 1999, 1:170-176

7. Bauer AK, Malkinson AM, Kleeberger SR: Susceptibility to neoplastic and non-neoplastic pulmonary diseases in mice: genetic similarities. Am J Physiol Lung Cell Mol Physiol 2004, 287:L685-L703

8. Engels EA, Wu X, Gu J, Dong Q, Liu J, Spitz MR: Systematic evaluation of genetic variants in the inflammation pathway and risk of lung cancer. Cancer Res 2007, 67:6520-6527

9. Keith RL, Miller YE, Hoshikawa Y, Moore MD, Gesell TL, Gao B, Malkinson AM, Golpon HA, Nemenoff RA, Geraci MW: Manipulation of 
pulmonary prostacyclin synthase expression prevents murine lung cancer. Cancer Res 2002, 62:734-740

10. Bernert H, Sekikawa K, Radcliffe RA, Iraqi F, You M, Malkinson AM: Tnfa and II-10 deficiencies have contrasting effects on lung tumor susceptibility: gender-dependent modulation of IL-10 haploinsufficiency. Mol Carcinog 2003, 38:117-123

11. Clark JC, Tichelaar JW, Wert SE, Itoh N, Perl AK, Stahlman MT Whitsett JA: FGF-10 disrupts lung morphogenesis and causes pulmonary adenomas in vivo. Am J Physiol Lung Cell Mol Physiol 2001, 280:L705-L715

12. Gordon S: Alternative activation of macrophages. Nat Rev Immunol 2003, 3:23-35

13. Takanami I, Takeuchi K, Kodaira S: Tumor-associated macrophage infiltration in pulmonary adenocarcinoma: association with angiogenesis and poor prognosis. Oncology 1999, 57:138-142

14. Wyckoff J, Wang W, Lin EY, Wang Y, Pixley F, Stanley ER, Graf T, Pollard JW, Segall J, Condeelis J: A paracrine loop between tumor cells and macrophages is required for tumor cell migration in mammary tumors. Cancer Res 2004, 64:7022-7029

15. Terabe M, Berzofsky JA: Immunoregulatory T cells in tumor immunity. Curr Opin Immunol 2004, 16:157-162

16. Sica A, Bronte V: Altered macrophage differentiation and immune dysfunction in tumor development. J Clin Invest 2007, 117:1155-1166

17. Mills CD, Kincaid K, Alt JM, Heilman MJ, Hill AM: M-1/M-2 macrophages and the Th1/Th2 paradigm. J Immunol 2000, 164:6166-6173

18. Stout RD, Jiang C, Matta B, Tietzel I, Watkins SK, Suttles J: Macrophages sequentially change their functional phenotype in response to changes in microenvironmental influences. J Immunol 2005 , 175:342-349

19. Kotowicz K, Callard RE, Friedrich K, Matthews DJ, Klein N: Biological activity of IL-4 and IL-13 on human endothelial cells: functional evidence that both cytokines act through the same receptor. Int Immunol 1996, 8:1915-1925

20. Munder M, Eichmann K, Moran JM, Centeno F, Soler G, Modolell M: Th1/Th2-regulated expression of arginase isoforms in murine macrophages and dendritic cells. J Immunol 1999, 163:3771-3777

21. Mantovani A, Sica A, Sozzani S, Allavena P, Vecchi A, Locati M: The chemokine system in diverse forms of macrophage activation and polarization. Trends Immunol 2004, 25:677-686

22. Montaner LJ, da Silva RP, Sun J, Sutterwala S, Hollinshead M, Vaux $\mathrm{D}$, Gordon S: Type 1 and type 2 cytokine regulation of macrophage endocytosis: differential activation by IL-4/IL-13 as opposed to IFNgamma or IL-10. J Immunol 1999, 162:4606-4613

23. Nair MG, Cochrane DW, Allen JE: Macrophages in chronic type 2 inflammation have a novel phenotype characterized by the abundant expression of $\mathrm{Ym} 1$ and Fizz1 that can be partly replicated in vitro. Immunol Lett 2003, 85:173-180

24. Morris SM Jr, Kepka-Lenhart D, Chen LC: Differential regulation of arginases and inducible nitric oxide synthase in murine macrophage cells. Am J Physiol 1998, 275:E740-E747

25. Luo Y, Zhou H, Krueger J, Kaplan C, Lee SH, Dolman C, Markowitz D, Wu W, Liu C, Reisfeld RA, Xiang R: Targeting tumor-associated macrophages as a novel strategy against breast cancer. J Clin Invest 2006, 116:2132-2141

26. Huang M, Wang J, Lee P, Sharma S, Mao JT, Meissner H, Uyemura K, Modlin R, Wollman J, Dubinett SM: Human non-small cell lung cancer cells express a type 2 cytokine pattern. Cancer Res 1995 , 55:3847-3853

27. Robinson-Smith TM, Isaacsohn I, Mercer CA, Zhou M, Van RN, Husseinzadeh N, Farland-Mancini MM, Drew AF: Macrophages mediate inflammation-enhanced metastasis of ovarian tumors in mice. Cancer Res 2007, 67:5708-5716

28. Hagemann T, Wilson J, Burke F, Kulbe H, Li NF, Pluddemann A, Charles K, Gordon S, Balkwill FR: Ovarian cancer cells polarize macrophages toward a tumor-associated phenotype. J Immunol 2006, 176:5023-5032

29. Redente EF, Orlicky DJ, Bouchard RJ, Malkinson AM: Tumor signaling to the bone marrow changes the phenotype of monocytes and pulmonary macrophages during urethane-induced primary lung tumorigenesis in A/J mice. Am J Pathol 2007, 170:693-708

30. Malkinson AM: Primary lung tumors in mice as an aid for understanding, preventing, and treating human adenocarcinoma of the lung. Lung Cancer 2001, 32:265-279

31. Malkinson AM, Beer DS: Major effect on susceptibility to urethan- induced pulmonary adenoma by a single gene in BALB/cBy mice. J Natl Cancer Inst 1983, 70:931-936

32. Bauer AK, Dwyer-Nield LD, Keil K, Koski K, Malkinson AM: Butylated hydroxytoluene (BHT) induction of pulmonary inflammation: a role in tumor promotion. Exp Lung Res 2001, 27:197-216

33. Malkinson AM, Koski KM, Evans WA, Festing MF: Butylated hydroxytoluene exposure is necessary to induce lung tumors in BALB mice treated with 3-methylcholanthrene. Cancer Res 1997, 57:2832-2834

34. Bauer AK, Dwyer-Nield LD, Hankin JA, Murphy RC, Malkinson AM: The lung tumor promoter, butylated hydroxytoluene (BHT), causes chronic inflammation in promotion-sensitive BALB/cByJ mice but not in promotion- resistant CXB4 mice. Toxicology 2001, 169:1-15

35. Gingrich JR, Barrios RJ, Foster BA, Greenberg NM: Pathologic progression of autochthonous prostate cancer in the TRAMP model. Prostate Cancer Prostatic Dis 1999, 2:70-75

36. Greenberg NM, DeMayo F, Finegold MJ, Medina D, Tilley WD, Aspinall JO, Cunha GR, Donjacour AA, Matusik RJ, Rosen JM: Prostate cancer in a transgenic mouse. Proc Natl Acad Sci USA 1995, 92:3439-3443

37. Greenberg NM, DeMayo FJ, Sheppard PC, Barrios R, Lebovitz R Finegold M, Angelopoulou R, Dodd JG, Duckworth ML, Rosen JM: The rat probasin gene promoter directs hormonally and developmentally regulated expression of a heterologous gene specifically to the prostate in transgenic mice. Mol Endocrinol 1994, 8:230-239

38. Raina K, Singh RP, Agarwal R, Agarwal C: Oral grape seed extract inhibits prostate tumor growth and progression in TRAMP mice. Cancer Res 2007, 67:5976-5982

39. Fisher GH, Wellen SL, Klimstra D, Lenczowski JM, Tichelaar JW, Lizak MJ, Whitsett JA, Koretsky A, Varmus HE: Induction and apoptotic regression of lung adenocarcinomas by regulation of a K-Ras transgene in the presence and absence of tumor suppressor genes. Genes Dev 2001, 15:3249-3262

40. Mitchell BS, Horny HP, Schumacher U: Immunophenotyping of human HT29 colon cancer cell primary tumours and their metastases in severe combined immunodeficient mice. Histochem J 1997, 29: 393-399

41. Jojovic M, Schumacher U: Quantitative assessment of spontaneous lung metastases of human HT29 colon cancer cells transplanted into SCID mice. Cancer Lett 2000, 152:151-156

42. Raes G, Brys L, Dahal BK, Brandt J, Grooten J, Brombacher F, Vanham G, Noel W, Bogaert P, Boonefaes T, Kindt A, Van den BR, Leenen PJ, De BP, Ghassabeh GH: Macrophage galactose-type C-type lectins as novel markers for alternatively activated macrophages elicited by parasitic infections and allergic airway inflammation. J Leukoc Biol 2005, 77:321-327

43. Rotondo R, Barisione G, Mastracci L, Grossi F, Orengo AM, Costa R, Truini M, Fabbi M, Ferrini S, Barbieri O: IL-8 induces exocytosis of arginase 1 by neutrophil polymorphonuclears in nonsmall cell lung cancer. Int J Cancer 2009, 125:887-893

44. Martinez FO, Gordon S, Locati M, Mantovani A: Transcriptional profiling of the human monocyte-to-macrophage differentiation and polarization: new molecules and patterns of gene expression. J Immunol 2006, 177:7303-7311

45. Miller YE, Dwyer-Nield LD, Keith RL, Le M, Franklin WA, Malkinson AM: Induction of a high incidence of lung tumors in C57BL/6 mice with multiple ethyl carbamate injections. Cancer Lett 2003, 198: 139-144

46. Forkert PG, Jackson AC, Parkinson A, Chen S: Diminished expression of CYP1A1 in urethane-induced lung tumors in strain A/J mice: analysis by in situ hybridization and immunohistochemical methods. Am J Respir Cell Mol Biol 1996, 14:444-453

47. O'Donnell EP, Zerbe LK, Dwyer-Nield LD, Kisley LR, Malkinson AM: Quantitative analysis of early chemically-induced pulmonary lesions in mice of varying susceptibilities to lung tumorigenesis. Cancer Lett 2006, 241:197-202

48. Nikitin AY, Alcaraz A, Anver MR, Bronson RT, Cardiff RD, Dixon D Fraire AE, Gabrielson EW, Gunning WT, Haines DC, Kaufman MH, Linnoila RI, Maronpot RR, Rabson AS, Reddick RL, Rehm S, Rozengurt N, Schuller HM, Shmidt EN, Travis WD, Ward JM, Jacks T: Classification of proliferative pulmonary lesions of the mouse: recommendations of the mouse models of human cancers consortium. Cancer Res 2004, 64:2307-2316

49. Dinapoli MR, Calderon CL, Lopez DM: The altered tumoricidal capacity of macrophages isolated from tumor-bearing mice is related to 
reduce expression of the inducible nitric oxide synthase gene. J Exp Med 1996, 183:1323-1329

50. Zea AH, Rodriguez PC, Atkins MB, Hernandez C, Signoretti S, Zabaleta J, McDermott D, Quiceno D, Youmans A, O'Neill A, Mier J, Ochoa AC: Arginase-producing myeloid suppressor cells in renal cell carcinoma patients: a mechanism of tumor evasion. Cancer Res 2005, 65:3044-3048

51. Chang $\mathrm{Cl}$, Liao JC, Kuo L: Macrophage arginase promotes tumor cell growth and suppresses nitric oxide-mediated tumor cytotoxicity. Cancer Res 2001, 61:1100-1106

52. Biswas SK, Sica A, Lewis CE: Plasticity of macrophage function during tumor progression: regulation by distinct molecular mechanisms. J Immunol 2008, 180:2011-2017

53. Boraschi D, Meltzer MS: Defective tumoricidal capacity of macrophages from A/J mice. I. Characterization of the macrophage cytotoxic defect after in vivo and in vitro activation stimuli. J Immunol 1979, 122:1587-1591

54. Boraschi D, Meltzer MS: Defective tumoricidal capacity of macrophages from $\mathrm{A} / \mathrm{J}$ mice. II. Comparison of the macrophage cytotoxic defect of $\mathrm{A} / \mathrm{J}$ mice with that of lipid $\mathrm{A}$-unresponsive $\mathrm{C} 3 \mathrm{H} / \mathrm{HeJ}$ mice. $\mathrm{J}$ Immunol 1979, 122:1592-1597
55. Boraschi D, Meltzer MS: Defective tumoricidal capacity of macrophages from A/J mice. III. Genetic analysis of the macrophage defect. J Immunol 1980, 124:1050-1053

56. Meyer AM, Dwyer-Nield LD, Hurteau G, Keith RL, Ouyang Y, Freed BM, Kisley LR, Geraci MW, Bonventre JV, Nemenoff RA, Malkinson AM: Attenuation of the pulmonary inflammatory response following butylated hydroxytoluene treatment of cytosolic phospholipase A2 null mice. Am J Physiol Lung Cell Mol Physiol 2006, 290:L1260L1266

57. Watkins SK, Egilmez NK, Suttles J, Stout RD: IL-12 rapidly alters the functional profile of tumor-associated and tumor-infiltrating macrophages in vitro and in vivo. J Immunol 2007, 178:1357-1362

58. Mills CD, Shearer J, Evans R, Caldwell MD: Macrophage arginine metabolism and the inhibition or stimulation of cancer. J Immunol 1992, 149:2709-2714

59. Mantovani A, Sozzani S, Locati M, Allavena P, Sica A: Macrophage polarization: tumor-associated macrophages as a paradigm for polarized M2 mononuclear phagocytes. Trends Immunol 2002, 23:549-555

60. Swann JB, Smyth MJ: Immune surveillance of tumors. J Clin Invest 2007, 117:1137-1146 